\title{
Genetic Ablation of Apolipoprotein A-IV Accelerates Alzheimer's Disease Pathogenesis in a Mouse Model
}

Yujie Cui, Mingwei Huang, Yingbo He, Shuyan Zhang, and Yongzhang Luo

From the National Engineering Laboratory for Anti-tumor Protein Therapeutics, Beijing Key Laboratory for Protein Therapeutics, and Cancer Biology Laboratory, School of Life Sciences, Tsinghua University, Beijing, China

The link between lipoprotein metabolism and Alzheimer's disease (AD) has been established. Apolipoprotein A-IV (apoA-IV), a component of lipoprotein particles similar to apolipoprotein $\mathrm{E}$, has been suggested to play an important role in brain metabolism. Although there are clinical debates on the function of its polymorphism in AD, the pathologic role of apoA-IV in $\mathrm{AD}$ is still unknown. Here, we report that genetic ablation of apoA-IV is able to accelerate AD pathogenesis in mice. In a mouse model that overexpresses human amyloid precursor protein (APP) and presenilin 1, genetic reduction of apoA-IV augments extracellular amyloid- $\beta$ peptide $(A \beta)$ burden and aggravates neuron loss in the brain. In addition, genetic ablation of apoA-IV also accelerates spatial learning deficits and increases the mortality of mice. We have found that apoA-IV colocalizes within $A \beta$ plaques in APP/presenilin 1 transgenic mice and binds to $A \beta$ in vitro. Subsequent studies show that apoA-IV in this model facilitates $A \beta$ uptake in the $A \beta$ clearance pathway mediated by astrocytes rather than the amyloidogenic pathway of APP processing. Taken together, we conclude that apoA-IV deficiency increases $A \beta$ deposition and results in cognitive damage in the mouse model. Enhancing levels of apoA-IV may have therapeutic potential in AD treatment. (Am J Pathol 2011, 178:1298-1308; DOI: 10.1016/j.ajpath.2010.11.057)

In recent years, genetic and biochemical evidences support the hypothesis that amyloid- $\beta$ peptide $(A \beta)$ accumulation in the brain is a toxic event in the pathogenesis of Alzheimer's disease (AD). ${ }^{1} A \beta$ is produced by sequential proteolytic processing of amyloid precursor protein (APP), a transmembrane protein that undergoes two distinct processing pathways. ${ }^{2,3}$ In one of the pathways, amyloidogenic processing, APP is first cleaved by $\beta$-secretase, $\beta$-site APP cleaving enzyme $1,{ }^{4}$ and then by $\gamma$-secretase to generate $A \beta$ peptides. Mutations associated with early-onset familial forms of AD (FAD) are found in the genes of APP, as well as the major components of $\gamma$-secretase, including presenilin 1 (PS1). ${ }^{5,6}$ These FAD mutations increase the generation of $A \beta$ peptides and the relative proportion of the form $A \beta 42 .{ }^{1}$ The clearance of $A \beta$, which is another important event for maintaining $A \beta$ metabolism in the brain, recently has attracted more attention as a potential therapeutic approach for treating $A D$. Astrocytes in the central nervous system have been considered to play an essential role in maintaining synaptic functions and central nervous system repair after injury. ${ }^{7,8}$ They also exhibit migratory, phagocytic, and proteolytic capacities. ${ }^{7-11}$ Adult mouse astrocytes have been reported to degrade $A \beta$ deposits effectively in brain sections from an $A D$ mouse model in vitro ${ }^{12}$. Analysis of $A D$ brain shows that the hypertrophic processes of astrocytes can degrade $A \beta$-containing plaques, ${ }^{13}$ indicating that astrocytes are involved in the degradation and clearance process of $\mathrm{A} \beta$. Because the level of $A \beta$ accumulation in the brain can be altered by generation and clearance, reducing brain $\mathrm{A} \beta$ production or enhancing its clearance may become viable strategies for $A D$ drug development. ${ }^{1}$

The link between lipoprotein metabolism and the pathologic process of $A D$ has been well established. Experimental studies provide a potential mechanism that

Supported in part by the General Programs of the National Natural Science Foundation of China (no. 30670419 and no. 30771083), the Major Program of National Natural Science Foundation of China (no. 30490171), the National High Technology Research and Development Program of China (no. 2007AA02Z155), the State Key Development Program for Basic Research of China (no. 2006CB910305), and the National Science \& Technology Major Project (no. 2009ZX09103-703 and no. 2009ZX09306-002).

Accepted for publication November 15, 2010.

Supplemental material for this article can be found at http://ajp. amjpathol.org or at doi: 10.1016/j.ajpath.2010.11.057.

Address reprint requests to Yongzhang Luo, Ph.D., School of Life Sciences, Tsinghua University, Beijing 100084, China. E-mail: yluo@ tsinghua.edu.cn. 
lipoproteins may influence $A D$ pathogenesis by affecting the metabolism of $A \beta$, including the processes of deposition and clearance in $A D$ brain, and also show that a portion of $A \beta$ in plasma and cerebrospinal fluid (CSF) is associated with lipoproteins. ${ }^{14-16}$ The well-known $\varepsilon 4$ allele of apolipoprotein $\mathrm{E}(\mathrm{apoE})$ is a strong genetic risk factor for late-onset $A D,{ }^{17,18}$ which is present on highdensity-like lipoprotein particles in association with other apolipoproteins. ${ }^{19}$ ApoE has been suggested to participate in $A \beta$ aggregation and clearance in $A D$ pathogenesis, although the roles of its isoforms are not fully elucidated. ${ }^{20}$ Studies showed that apoE can promote $A \beta$ polymerization in vitro in an isoform-specific way ${ }^{21,22}$; some in vivo experiments were reported to support this interpretation, ${ }^{23,24}$ whereas controversial studies were also reported. ${ }^{25,26}$ In addition, apolipoprotein J (clusterin) is found to be critical for neuritic toxicity in a mouse model of $A D,{ }^{27}$ whereas apolipoprotein $A-I$ has not been shown to be associated with $A D$ in transgenic mouse models. ${ }^{28}$ Apolipoprotein A-IV (apoA-IV) is another typical apolipoprotein in plasma and CSF, ${ }^{29,30}$ which is involved in lipid metabolism. ${ }^{31,32}$ Recent studies indicate that it also functions in several important physiologic processes, including anti-inflammation ${ }^{33}$ and antioxidation, ${ }^{34}$ and pathologic processes such as protein-misfolding disease ${ }^{35,36}$ and atherosclerosis. ${ }^{37}$ Furthermore, there have been neurologic reports from Tso and colleagues ${ }^{38,39}$ showing that it can regulate food intake and energy metabolism in the rat brain. In clinical studies, Csaszar et $\mathrm{al}^{40}$ reported that the apoA-IV codon 360 mutation is associated with increased susceptibility for the development of $A D$ in patients. However, Visvikis's group ${ }^{41}$ argued that this mutation is not associated with AD but rather with human aging, which raises the debate on the functions of apoA-IV mutation in AD pathogenesis. Taken together, although several functions of apoA-IV correlate with $A D$ pathogenesis and there are clinical debates on the functions of its mutation, the pathologic role of apoA-IV in $A D$ has not been investigated.

According to the functions of apoA-IV mentioned above, we were interested in whether knocking out apoA-IV would facilitate AD pathogenesis. Using a direct genetic approach, we investigated whether nondietary, nonpharmacologic differences have any effect on the development of $A \beta$-related pathogenesis. We constructed a transgenic mouse model to investigate the role of apoA-IV. We chose a 5X FAD transgenic mouse model, ${ }^{42}$ which more rapidly develops AD-like cerebral amyloidosis compared with typical kinds of transgenic mice that overexpress mutated APP and PS1. Genetic variations of apoA-IV levels in 5X FAD transgenic mice were achieved by modifying the dose of apoA-IV gene through crossing with apoA-IV $\mathrm{V}^{-1-}$ mice. Here, the results show that deficiency of apoA-IV accelerates AD pathogenesis in this mouse model. To elucidate the mechanism, both in vitro and in vivo assays were used, and we found that apoA-IV binds to $A \beta$ in vitro and facilitates $A \beta$ clearance mediated by astrocytes. Methods to increase apoA-IV levels may be a novel approach to treat AD.

\section{Materials and Methods}

\section{Mice}

Transgenic mice expressing APP/PS1 (B6SJL; Tg6554; FAD mutations APP K670N/M671L + I716V + V717I and PS1 M146L + L286V, named 5X FAD, ${ }^{42}$ The Jackson Laboratory, Bar Harbor, ME) were hybridized with the mice lacking the gene of apolipoprotein A-IV (B6.129', apoA-IV ${ }^{-1-}$ mice; The Jackson Laboratory) to ultimately generate 5X FAD APP/PS1 mice expressing two (apoA$\left.1 \mathrm{~V}^{+/+}\right)$, one $\left(\right.$apoA- $\left.I \mathrm{~V}^{+/-}\right)$, or no $\left(\right.$apoA-IV $\left.{ }^{-I-}\right)$ copies of the endogenous mouse apoA-IV gene. Animals were screened for the presence of the APP and PS1 transgenes and apoA-IV genes by PCR from tail genome DNA according to the protocols from The Jackson Laboratory. Mice were anesthetized with sodium pentobarbital. Following transcardial perfusion with PBS (pH 7.4), the brain was divided sagittally into two hemispheres. One hemisphere was immersion-fixed in paraformaldehyde ( $4 \%$ in PBS, pH 7.4) overnight, dehydrated in graded ethanol, cleared in xylene, and embedded in paraffin blocks for subsequent histologic analysis. The other hemisphere was frozen in liquid nitrogen for subsequent biochemical analysis. All animal studies were performed according to the rule of Beijing Administration Office of Laboratory Animals.

\section{Behavior Tests}

Morris water maze used in these tests was a white circular pool $(123 \mathrm{~cm}$ in diameter, $61 \mathrm{~cm}$ deep, and water at $20^{\circ} \mathrm{C} \pm 2^{\circ} \mathrm{C}$ ) for both experiments. A submerged white, circular platform (10 cm in diameter) was located $23 \mathrm{~cm}$ from the side of the maze. A computerized animal tracking system was used for recording. The procedure ${ }^{43}$ consisted of 5 days of training, with four trials per day, in which each animal was released from each of four different start positions; the order was randomly determined. Initial start positions were varied across days. During trials, if the animal failed to locate the platform, the experimenter gently led it to the platform. The mice floating in the training step were excluded for further tests; thus, they were not included in statistical analysis. Animals then remained on the platform for 15 seconds after finding it or being led to it. Sixty seconds was the maximum time that the mice were allowed to swim. Twenty-four hours after the last training, there was a probe trial. The platform was removed, and the animals were placed in a novel start position in the maze. This step ensures that the animal's spatial preference is a reflection of the memory of the goal location rather than a specific swim path. Then the animal was removed after 60 seconds of swimming. Finally, scores were calculated according to the frequency of mice staying in the different concentric circles with the center in the platform position (see Supplemental Figure S1 at $h t t p: / / a j p . a m j p a t h o l . o r g)$. Statistical analyses were performed with the repeated-measures analysis of variance for training sections and Student's $t$-test for probe trials. 


\section{Immunohistochemistry, Niss/ Staining, Thioflavin S Staining, and Image Analyses}

Paraffin-embedded blocks of the mice hemispheres were sectioned sagittally into $10-\mu \mathrm{m}$ slices. For $A \beta$ immunohistochemistry, sections were microwaved, and the endogenous tissue peroxidase activity was quenched by incubation with $1 \%$ peroxide, and then blocked, incubated with primary antibody: mouse monoclonal antibody 4G8 (Calbiochem, La Jolla, CA) overnight at $4^{\circ} \mathrm{C}$. The antigens were detected by secondary antibodies with the use of standard diaminobenzidine methods. Sections were also counterstained with hematoxylin (Sigma, St Louis, MO). For Niss staining, sections were recovered in distilled water and then stained with $0.1 \%$ cresyl violet solution (J\&K Chemical, BJ, China) followed by $95 \%$ ethanol differentiation. The images were visualized and digitally photographed by bright-field microscopy (Olympus IX71 optical microscope, Japan). For thioflavin S staining, sections were recovered in distilled water and then stained with $1 \%$ thioflavin S (Sigma) solution followed by $80 \%$ ethanol differentiation. Three sections $200 \mu \mathrm{m}$ apart per mouse, 6 mice per group, were performed. The images were visualized and digitally photographed by fluorescence microscopy (Olympus IX71 optical microscope, Japan). All of the images were analyzed by image software (Nikon NIS-Elements AR 3.0, Japan). Plaques are defined as the areas covered by $A \beta$ immunostained regions. Section areas are defined as the whole tissue sample areas in the picture.

\section{A $\beta$ ELISA and APP Detection}

The hemisphere was homogenized, and one part of the solution was ultracentrifuged as described. ${ }^{44} \mathrm{~A} \beta 42$ enzyme-linked immunosorbent assay (ELISA) was performed with $4 \mathrm{G} 8$ as the capture antibody and rabbit anti-A $\beta 42$ antibody (Novus Biologicals, Littleton, CO) as the detection antibody. HRP-conjugated goat antirabbit antibody was used as the secondary antibody. Synthetic human $A \beta 42$ (American Peptide, Sunnyvale, CA) was used to generate a standard curve for the detection. The plates were developed with the standard tetramethyl benzidine method, and the reaction was stopped by adding equal volume of $2 \mathrm{M} \mathrm{H}_{2} \mathrm{SO}_{4}$. The results were read with a microtiter plate reader. Another part of the homogenized solution was centrifuged at high speed, and the supernatant was mixed with loading buffer for Western blotting. Full-length APP and APP carboxy terminal fragments (CTFs) were detected with mouse monoclonal antibody 6F/3D (Abcam, Cambridge, MA). Glyceraldehyde-3-phosphate dehydrogenase was detected with mouse monoclonal antibody against glyceraldehyde-3-phosphate dehydrogenase (Santa Cruz Biotechnology, Santa Cruz, CA). ApoA-IV was detected with goat polyclonal antibody against apoA-IV (Santa Cruz Biotechnology).

\section{Immunofluorescence Staining for Tissue Sections}

Ten-micron sections from APP/PS1 and APP/PS1 apoA$\mathrm{IV}^{-1-}$ mice were incubated with goat antibody against apoA-IV (Novus Biologicals) and mouse antibody against $A \beta$ (4G8) as the primary antibodies, and then tetramethylrhodamine isothiocyanate-conjugated rabbit-anti-goat antibody and fluorescein isothiocyanate-conjugated rabbit-anti-mouse antibody were used as the secondary antibodies.

Ten-micron sections from APP/PS1 mice and APP/ PS1 apoA-IV ${ }^{-1-}$ mice were incubated with rabbit antibody against glial fibrillary acidic protein (GFAP; Santa Cruz Biotechnology) and mouse antibody against $A \beta$ (4G8) as the primary antibodies, and then tetramethylrhodamine isothiocyanate-conjugated goat-anti-rabbit antibody and fluorescein isothiocyanate-conjugated goat-anti-mouse antibody were used as the secondary antibodies. The immunofluorescent images were obtained with the use of confocal laser scanning microscope (Nikon microscope A1R/A1, Japan) and analyzed by image software (NIS-Elements AR 3.0, Japan). Five plaques per section, three sections 200 $\mu \mathrm{m}$ apart per mouse, and five mice in each group were included for quantification of relative astrocytes levels.

\section{ApoA-IV and Clusterin Preparation}

Recombinant human apoA-IV (rh-apoA-IV) was expressed in Escherichia coli and purified as described. ${ }^{45}$ Plasma clusterin (apolipoprotein $\mathrm{J}$ ) was purified from human plasma with the use of monoclonal antibody against clusterin (BD Pharmingen, San Diego, CA) as described. ${ }^{46}$

\section{ELISA for Binding Tests}

A $\beta 42$ and rh-apoA-IV were coated in ELISA plates at a concentration of $10 \mu \mathrm{g} / \mathrm{ml}$. Then rh-apoA-IV and $A \beta 42$ were added correspondingly at different concentrations from 0.01 to $100 \mu \mathrm{g} / \mathrm{ml}$ for 2 hours of incubation at room temperature. After washing, anti-apoA-IV antibody and 4G8 were added as primary antibodies, correspondingly followed by incubation of secondary antibodies and diaminobenzidine detection.

\section{Primary Cell Culture}

Primary astrocytes were isolated from adult mice brain tissues. Brain tissues were obtained from C57BL/6 mice and apoA-IV ${ }^{-1-}$ mice aged 8 weeks, in $\mathrm{Ca}^{2+}$ - and $\mathrm{Mg}^{2+}$ free Hanks' balanced salt solution. The suspension was treated with $0.25 \%$ trypsin and $1 \mathrm{mmol} / \mathrm{L}$ EDTA for 20 minutes at $37^{\circ} \mathrm{C}$ and then triturated with $20 \mathrm{U} / \mathrm{ml}$ DNase I. Cells were washed with growth medium consisting of Dulbecco's modified Eagle's medium/F12, 10\% fetal bovine serum, $100 \mathrm{U} / \mathrm{ml}$ penicillin, and $100 \mu \mathrm{g} / \mathrm{ml}$ streptomycin and centrifuged at 1000 rpm for 8 minutes. Dissociated cells were filtered through a $100-\mu \mathrm{m}$ cell strainer, treated with Percoll (GE Healthcare, Piscataway, NJ) and 
resuspended in growth medium to establish primary cultures.

\section{In Vitro A $\beta$ Degradation Assay}

Primary mouse astrocytes were isolated as mentioned above. The synthesized A $\beta 42(10 \mathrm{mg} / \mathrm{ml})$ stocked in dimethyl sulfoxide was used for the treatment. After culture for 1 week, primary astrocytes were placed in a 96-well plate with $5 \times 10^{4}$ cells per well. Then the wells were treated with $10 \mu \mathrm{g} / \mathrm{ml} \mathrm{A} \beta 42$ in serum-free medium containing $10 \mu \mathrm{g} / \mathrm{ml}$ bovine serum albumin for 24 hours, respectively, in the presence or absence of rh-apoA-IV. During the performance, rh-apoA-IV was applied at the same time as $A \beta 42$ was diluted in the medium. After incubation, culture medium was collected, and astrocytes were washed and collected. A $\beta 42$ levels in the culture medium and cell lysates were determined by sandwich ELISA as described above.

\section{Immunofluorescence Staining for Primary Astrocytes}

The primary astrocytes were placed on coverslips in a 12-well plate and treated as mentioned above. After 24 hours of treatment, the coverslips were washed extensively with PBS, and fixed with $4 \%$ paraformaldehyde for 5 minutes and $1 \%$ TritonX-100 for 10 minutes. We incubated the coverslips with goat antibody against apoA-IV (Novus Biologicals) and mouse antibody against $A \beta$ (4G8) as the primary antibodies and then used tetramethylrhodamine isothiocyanate-conjugated rabbit-antigoat antibody and fluorescein isothiocyanate-conjugated rabbit-anti-mouse antibody as the secondary antibodies. Then the sections were also stained with DAPI. The immunofluorescent images were obtained with the use of confocal laser scanning microscope (Nikon microscope A1R/A1, Japan) and analyzed by image software (NIS-Elements AR 3.0, Japan).

\section{In Vitro IDE Assay}

Recombinant insulin-degrading enzyme (IDE; $500 \mathrm{ng} /$ $\mathrm{ml}$; R\&D Systems, Minneapolis, MN) was incubated with $10 \mu \mathrm{g} / \mathrm{ml} \mathrm{A} \beta 42$ for 1 hour in the absence or presence of rh-apoA-IV. The samples were mixed with equal amounts of loading buffer and then applied to $12 \%$ Tricine SDS-polyacrylamide gel electrophoresis. The levels of apoA-IV and $A \beta$ were monitored by Western blotting.

\section{Quantitative Real-Time PCR}

Brain hemispheres (8 months old) were grinded in liquid nitrogen. Total RNAs were isolated by Trizol according to the instructions and applied to RT-PCR with the use of a reverse transcription kit (Promega, Madison, WI). For real-time PCR, $0.5 \mu \mathrm{l}$ of CDNA was amplified in a 20- $\mu \mathrm{l}$ PCR reaction volume containing $1 \mu \mathrm{l}$ of $20 \times$ EvaGreen (Biotium, Hayward, CA). The reaction was performed with
Mx3000P real-time PCR system (Stratagene, La Jolla, CA). 18S rRNA served as an internal control. Quantitative real-time PCR was performed with primers as follows: neprilysin (NEP)-up, 5'-CTCTCTGTGCTTGTCTTGCTC3'; NEP-down, 5'-GACGTTGCGTTTCAACCAGC-3'; IDEup, 5'-AATCCGGCCATCCAGAGAATA-3'; IDE-down, 5'GGGTCTGACAGTGAACCTATGT-3'; GFAP-up, 5'-TCGGCCAGTTACCAGGAGG-3'; GFAP-down, 5'-ATGGTGATGCGGTTTTCTTCG-3'; 18S rRNA-up, 5'-CGGCTACCACATCCA AGGAA-3'; 18S rRNA-down, 5'-GCTGGAATTACCGCGGCT-3'.

\section{Transmission Electron Microscopy}

$\mathrm{A} \beta 42$ and rh-apoA-IV in PBS (pH 7.4) were co-incubated at $37^{\circ} \mathrm{C}$ for 48 hours. A sample of approximately $5 \mu$ l was placed on the surface of glowed carbon-filmed grid. The liquid was removed after 30 seconds. The residual material remaining on the carbon films was negatively stained with $2 \%$ aqueous phosphotungstic acid. The transmission electron microscope (Hitachi H-800, Japan), operated at an acceleration voltage of $100 \mathrm{kV}$, was used for the detection.

\section{Statistical Analyses}

Statistical analyses were performed with Student's t-test, repeated-measures analysis of variance, and LIFETEST procedures using SAS statistics software (SAS Institute, Cary, NC). $P<0.05$ was considered significant. The results are expressed as mean values \pm SEMs.

\section{Results}

\section{Genetic Ablation of ApoA-IV Increases Plaque Deposition in APP/PS1 Transgenic Mice}

To detect the function of apoA-IV in Alzheimer's disease in an animal model, we hybridized apoA-IV ${ }^{-1-}$ mice with 5X FAD APP/PS1 transgenic mice. Ultimately, APP/PS1 apoA-IV ${ }^{+/-}$and APP/PS1 apoA-IV ${ }^{-1-}$ mice were obtained, and these were verified by tail genome genotyping (Figure 1A).

This AD transgenic model, in which both APP and PS1 are overexpressed, is considered as a kind of accelerated $A D$ mouse model. ${ }^{42} A \beta$ plaque deposition is one of the hallmarks of $A D$. Here, we tested the amount and pattern of $A \beta$ deposition. Immunohistochemistry results showed that $A \beta$-immunoreactive deposits could be detected in the brain. Intriguingly, the amount of $A \beta$ in APP/PS1 apoA-IV ${ }^{-1-}$ mice was increased by $45 \%$ compared with that in APP/PS1 mice at the age of 6 to 8 months. In addition, the results of thioflavin S staining, which indicates the fibrous form of $A \beta$, corroborated with immunohistochemistry results, showed that not only the amount of $A \beta$ was increased but also the fibrous form of $A \beta$ (Figure 1, B-E). The amount of $A \beta 42$ in mice brain was analyzed by ELISA in the mice that developed $A \beta$ deposits (Figure $1 F)$. The data showed that genetic ablation of apoA-IV 


\section{A}

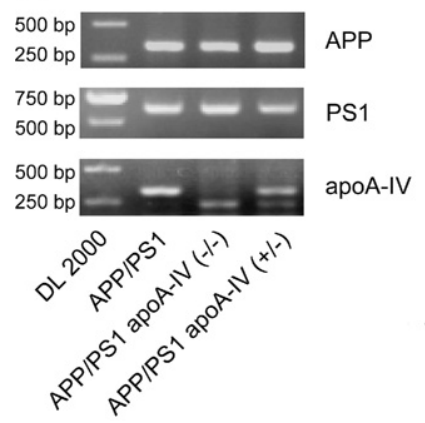

D

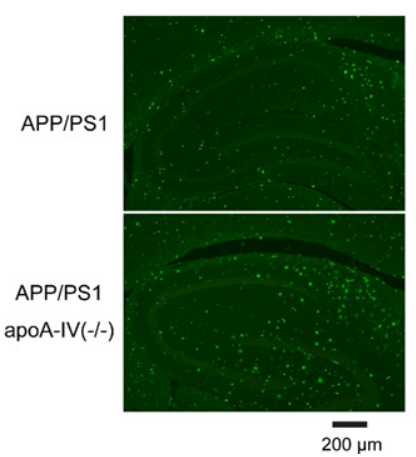

B

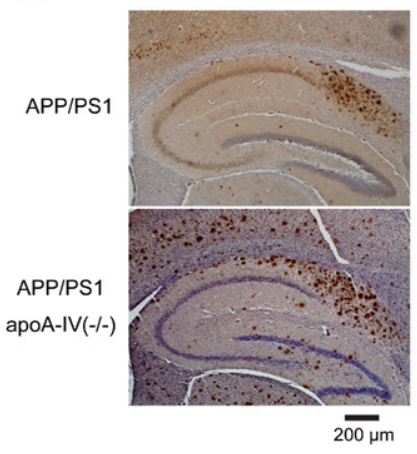

E

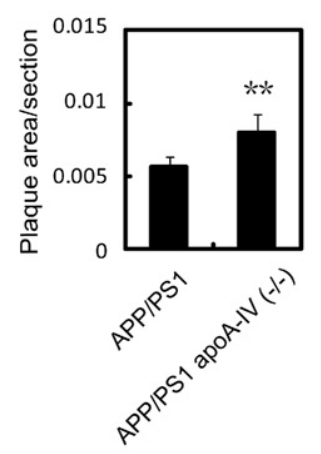

C

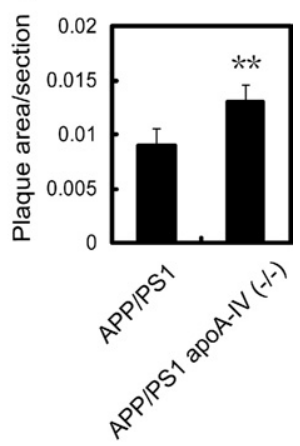

F

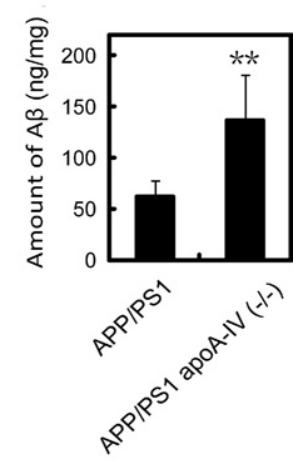

Figure 1. Genetic ablation of apoA-IV increases plaque deposition in APP/PS1 transgenic mice. A: Genotyping of hybrid mice by PCR; DL2000 DNA marker; length of the detected fragments: APP, 350 bp; PS1, 608 bp; apoA-IV ${ }^{+/+}, 329$ bp; apoA-IV ${ }^{-/-}, 250 \mathrm{bp}$; Parasagittal serial sections of brains ( $n=6$ per group) 6- to 8-month male mice were immunostained with antibody $4 \mathrm{G} 8$ (B) and counterstained with hematoxylin and stained by thioflavin S (D). C: The areas of the plaques stained by $4 \mathrm{G} 8$ were quantified by image software. ${ }^{\text {*** }} P<0.01$ for $\mathrm{APP} / \mathrm{PS} 1$ versus APP/PS1 apoA-IV ${ }^{-/-}$. E: The areas of the plaques stained by thioflavin $\mathrm{S}$ were quantified ${ }_{* * *} P<0.01$ for $\mathrm{APP} / \mathrm{PS} 1$ versus $\mathrm{APP} / \mathrm{PS} 1$ apoA$\mathrm{IV}^{-/-}$. F: The amount of $\mathrm{A} \beta 42$ in hemisphere was detected by ELISA. ${ }^{* *} P<0.01$ for APP/PS1 versus APP/PS1 apoA-IV ${ }^{-/-}$ increased the $A \beta$ burden in this transgenic mouse model, further confirming the results of immunohistochemistry and thioflavin S staining. All of these data suggest that genetic deficiency of apoA-IV contribute to an increased $A \beta$ burden in $A D$ transgenic mice brain.

\section{Ablation of ApoA-IV in APP/PS1 Transgenic Mice Aggravates Neuron Loss in Brain}

In a previous report from Vassar and colleagues, ${ }^{42}$ APP/PS1 overexpression in mice has resulted in neuron loss. Given the observation of increased $A \beta$ burden in mice brain after genetic ablation of apoA-IV, we hypothesized that the loss of neurons could be aggravated by ablation of apoA-IV in APP/PS1 transgenic mice. Nissl staining was used to stain Nissl bodies in neurons to indicate the number of neurons. The results showed that the large pyramidal neurons in cortical layer 5 and neurons in hippocampus contained more disrupted morphologies, which indicate more neuron loss, in APP/PS1 apoA-IV ${ }^{-1-}$ mice compared with APP/ PS1 mice (Figure 2, A and B), whereas apoA-IV ${ }^{-1-}$ mice did not have obvious differences from wild-type (WT) mice (see Supplemental Figure S2, A and B, at http://ajp.amjpathol.org). The quantified results showed that the loss of neurons was increased after ablation of apoA-IV in APP/PS1 transgenic mice in the areas of the cortex and CA1, CA3 of the hippocampus (Figure 2C). The phenomenon suggests that apoA-IV is involved in the accumulation of $A \beta$, which affects the neuron cells and ultimately results in accelerated neuron loss in this kind of $A D$ mouse model.

\section{Genetic Ablation of ApoA-IV Accelerates Spatial Learning Deficits and Mortality of APP/PS1 Transgenic Mice}

Alzheimer' disease often exhibits spatial learning deficits and increased mortality in both transgenic mouse models and clinical patients. ${ }^{47,48}$ To determine whether the absence of apoA-IV influences the spatial learning ability of APP/PS1-overexpressing mice, the Morris water maze test, a typical behavior test, was used. After 5 days of training, the mice showed different spatial learning abilities. The escape latency of all groups of mice decreased as time went by, but APP/PS1 apoA-IV ${ }^{-1-}$ mice exhibited a more slowly decreasing rate compared with APP/PS1 mice, whereas apoA-IV ${ }^{-1-}$ mice did not show significant differences from WT mice (Figure 3A). In probe trials, the swimming traces were recorded, and the result showed that APP/PS1 apoA-IV ${ }^{-1-}$ mice spent more time in quadrant I than did APP/PS1 mice. The test score given in the Morris water maze was to evaluate the spatial learning ability of the mice (see Supplemental Figure S1 at $h t t p: / /$ ajp.amjpathol.org). Genetic ablation of apoA-IV in APP/ PS1-overexpressing mice showed a significantly lower score, which suggests an accelerated memory loss of this group at the age of 6 to 8 months (Figure 3B).

The early mortality noted in APP/PS1 mice is partially linked to the deposition of $A \beta$ protein in the brain. ${ }^{47}$ Thus, survival rates of the genetically manipulated mice were 
A
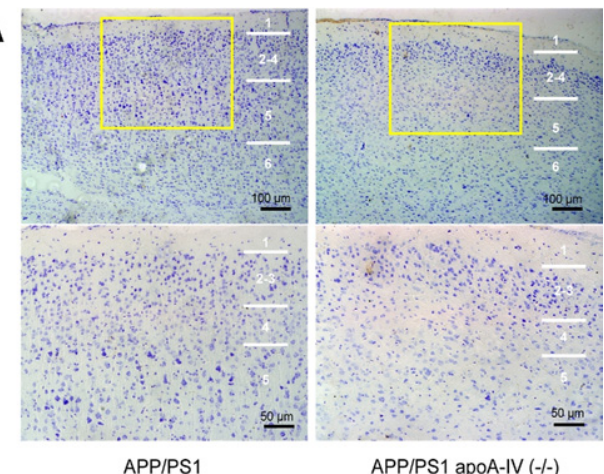

B

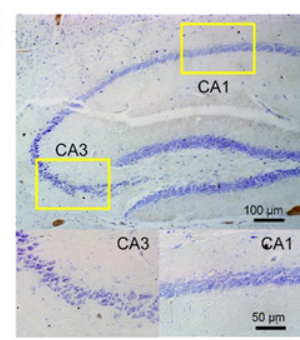

APP/PS1

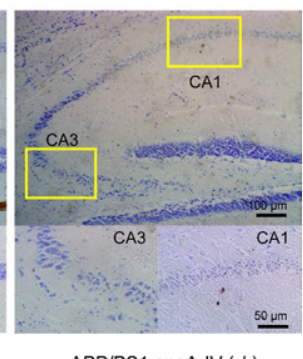

APP/PS1 apoA-IV (-/-)

\section{C}

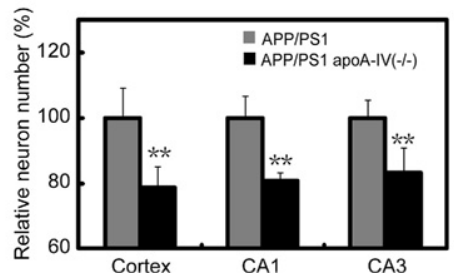

Figure 2. Deficiency of apoA-IV in APP/PS1 transgenic mice accelerates neuron loss in brain. Parasagittal sections of representative 8-month-old transgenic brains were stained with cresyl violet. A: Cortex was imaged. Numbers indicate cortical layers, and lines identify boundaries between layers. Note that large pyramidal neurons in cortical layer 5 are visibly reduced in number in the APP/PS1 apoA-IV ${ }^{-/-}$brain. B: Hippocampus was imaged. Boxes of each panel in upper images delineate areas shown at higher magnification in lower images, respectively. C: The relative neuron number (neurons of APP/PS1 apoA-IV ${ }^{-/} /$neurons of APP/PS1) in cortex, $\mathrm{CA} 1$, and $\mathrm{CA} 3$ of hippocampus was quantified. ${ }^{* *} P<0.01$ for APP/PS1 versus APP/PS1 apoA-IV

calculated (Figure 3C). No significant differences were observed in mice mortality between the WT group and the apoA-IV ${ }^{-1-}$ group. However, APP/PS1 apoA-IV ${ }^{-1-}$ mice and APP/PS1 apoA-IV ${ }^{+/-}$mice had more early-age death rates compared with APP/PS1 mice, which was shown by the significant change among these curves in Figure $3 \mathrm{C}$. These results show that the genetic ablation of apoA-IV itself does not change the survival rates, but, in APP/PS1 overexpressing mice, genetic ablation of apoA-IV aggravates the pathologic process, which, in turn, can affect mice survival rates.

\section{ApoA-IV Colocalizes within A $\beta$ Plaques in APP/ $P S 1$ Transgenic Mice and Binds to $A \beta$ In Vitro}

The data of plaque loads, neuron loss, and behavior tests all show that apoA-IV is related to the AD process in this transgenic mouse model, which prompted us to determine whether there is a direct interaction between apoA-IV and $A \beta$. With the use of the confocal laser scan- ning microscope, we found that apoA-IV colocalized with $A \beta$ plaques in APP/PS1 mice brain sections, which was shown in the merged fluorescent images of the brain section (Figure 4A). When apoA-IV was genetically ablated in APP/PS1 mice, there was no co-localizaition of apoA-IV with $A \beta$ plaques (see Supplemental Figure S3 at http://ajp.amjpathol.org).

In addition, the in vitro ELISA binding assay was performed to confirm the interaction between $A \beta$ and apoA-IV (Figure 4, B and C). Clusterin, also named apolipoprotein $\mathrm{J}$, was used as a positive control. ${ }^{49}$ The amount of apoA-IV bound to $A \beta$ increased in a dosedependent manner when $A \beta$ was coated on the ELISA plate and vice versa. These results suggest a direct interaction between apoA-IV and A $\beta$ in vivo. In addition, in vitro
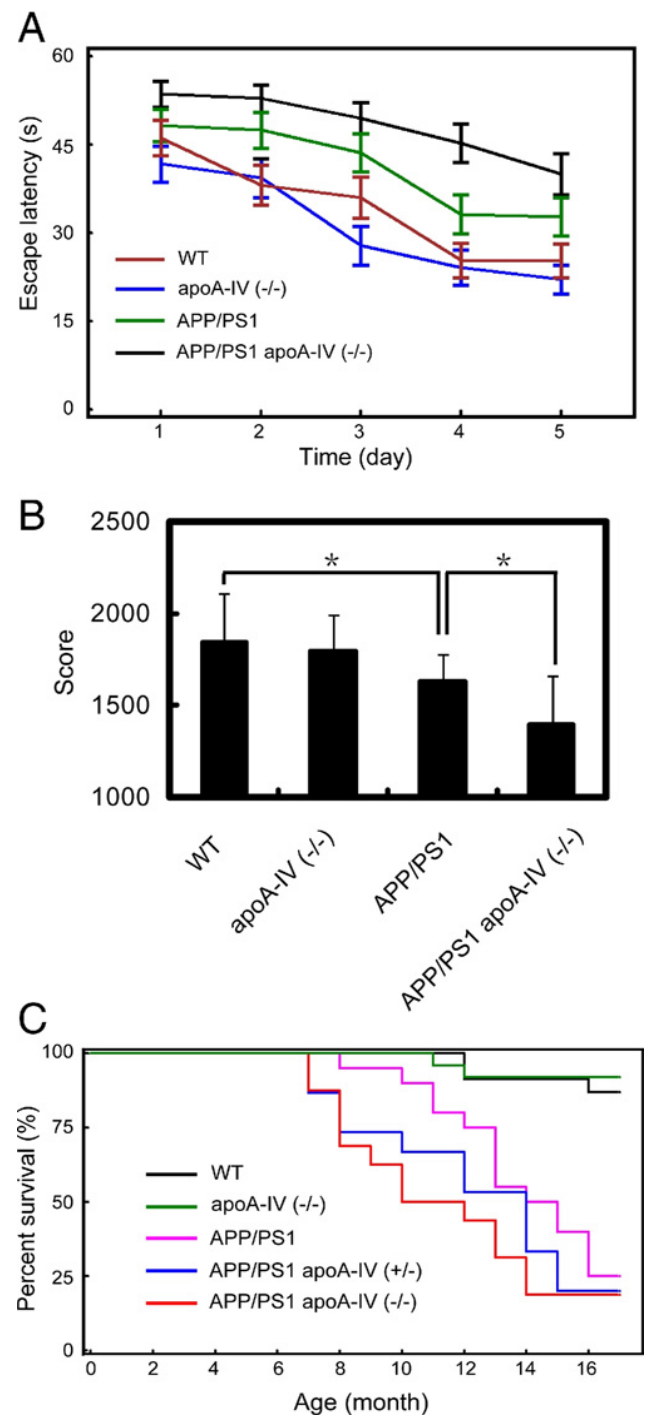

Figure 3. Genetic ablation of apoA-IV alters spatial learning and survival rates of APP/PS1 transgenic mice. A: Escape latency was detected in Morris water maze training tests with 10 male mice aged 6 to 8 months for each group, $P<0.05$, for WT versus APP/PS1, and for APP/PS1 versus APP/PS1 apoA-IV ${ }^{-/-}$. B: Scores were figured in a probe trial after 5 days of training, ${ }^{*} P<0.05$. C: Survival curves of WT $(n=23)$, apoA-IV ${ }^{-/}-(n=25)$, APP/PS1 $(n=20), \mathrm{APP} / \mathrm{PS} 1$ apoA-IV ${ }^{+/-}(n=15)$, and APP/PS1 apoA-IV ${ }^{-/}(n=16)$, $P<0.01$ for APP/PS1 versus APP/PS1 apoA-IV ${ }^{+/-}$and for APP/PS1 versus $\mathrm{APP} / \mathrm{PS} 1$ apoA-IV ${ }^{-/}$ 


\section{A}

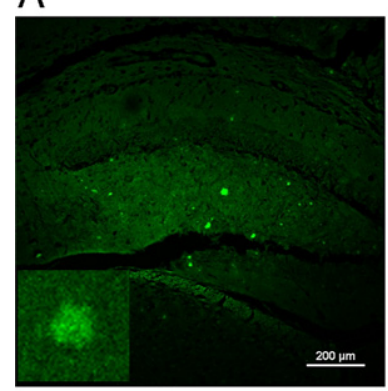

anti-A $\beta(4 G 8)$

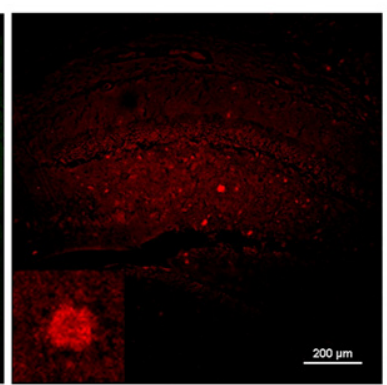

anti-apoA-IV

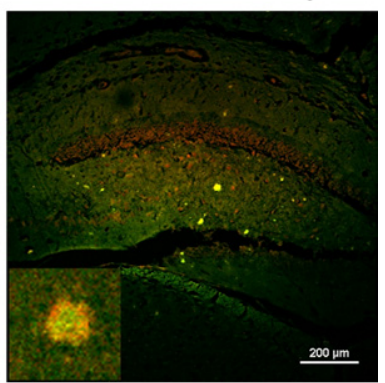

Merge
B

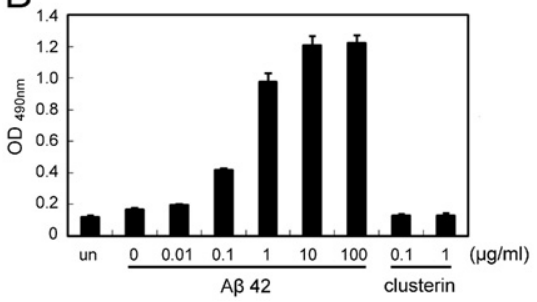

C

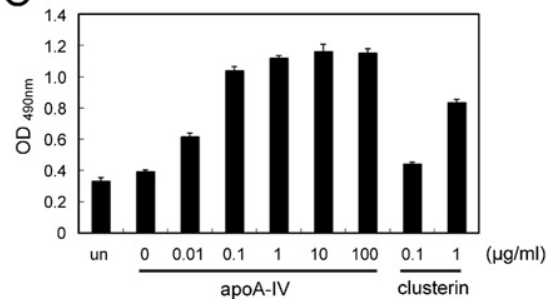

Figure 4. ApoA-IV colocalizes within A $\beta$ plaques in APP/PS1 transgenic mice and binds to $\mathrm{A} \beta$ in vitro. A: The $\mathrm{A} \beta$ plaques were stained by $4 \mathrm{G} 8$, and apoA-IV was recognized with antibody. The merged image, in which the spots turn yellow, shows the co-localization of plaques and the protein apoA-IV. The box delineates the area of hippocampus shown at higher magnification. Interaction between apoA-IV and $\mathrm{A} \beta 42$ was detected by ELISA coated with recombinant human apoA-IV $(\mathbf{B})$ or A $\beta 42$ (C), respectively; un: uncoated wells. co-incubation of apoA-IV and $A \beta$ at $37^{\circ} \mathrm{C}$ for 48 hours showed that apoA-IV disrupted the process of $A \beta$ fiber formation (see Supplemental Figure S4 at http://ajp. amjpathol.org), which showed additional evidence for the binding of apoA-IV to $A \beta 42$ in vitro. These results of our in vitro model indicate a direct role of apoA-IV in the pathologic process of $A \beta$.

\section{ApoA-IV Is Involved in the $A \beta$ Clearance Pathway Mediated by Astrocytes Rather than the Amyloidogenic Pathway of APP Processing}

On the basis of our in vitro and in vivo results, we concluded that apoA-IV serves as a beneficial factor, the lack of which can increase $A \beta$ burden, aggravate neuron loss, and accelerate cognitive deficits in this APP/PS1 transgenic model. As mentioned already, metabolism of $A \beta$ in vivo consists of two processes: generation and clearance. To elucidate the mechanism of apoA-IV affecting $A \beta$ burden, the amyloidogenic pathway of APP processing was analyzed in both APP/PS1 and APP/PS1 apoA$\mathrm{IV}^{-1-}$ mice. From the results of Western blotting, it was found that the levels of full-length APP were not significantly increased, nor were the levels of $\beta$-CTF, an APPprocessing product released from $\beta$-secretase digestion (Figure 5A). Because the levels of full-length APP and $\beta$-CTF reflect the relative level of $A \beta$ in the amyloidogenic pathway, this result suggests that the generation of $A \beta$ is not altered after genetic ablation of apoA-IV.

Because the results indicate that apoA-IV does not participate in the process of $A \beta$ generation, we hypothesized that apoA-IV is involved in the $A \beta$ clearance pathway. The results showed that $A \beta$ plaques in both APP/PS1 and APP/PS1 apoA-IV-I- groups were surrounded by activated astrocytes, with fewer activated astrocytes in the APP/PS1 apoA-IV ${ }^{-1-}$ group (Figure 5, $B$ and $C$ ). This phenomenon, together with the result of the co-locolization of apoA-IV with $A \beta$ plaques (Figure $4 A$ ), strongly implies that apoA-IV is involved in the $A \beta$ clearance pathway mediated by astrocytes. Moreover, the mRNA levels of GFAP, the astrocytes activation marker, were not significantly changed (Figure $5 \mathrm{H}$ ). These results indicate that apoA-IV facilitates the recruitment of activated astrocytes to the areas of plaques, whereas it does not participate in the process of astrocytes activation. To elucidate the role of apoA-IV in this clearance pathway, the in vitro $A \beta$ uptake assay was performed with or without exogenous apoA-IV in the culture media. The remaining amount of $A \beta 42$ in the culture media and in the cell lysates was measured after 24 hours of incubation with primary mouse astrocytes (Figure 5, D and E; see Supplemental Figure S5 at http://ajp.amjpathol.org). Co-immunostaining of apoA-IV and $A \beta 42$ in the cultured primary mouse astrocytes isolated from apoA-IV ${ }^{-1-}$ mice was shown in Figure 5F. These results showed that with exogenous apoA-IV, the remaining amount of $A \beta 42$ in culture media was reduced and the intracellular $A \beta 42$ was accumulated. This suggests the process of uptake is facilitated by binding to apoA-IV, whereas the intracellular degradation is not dramatically enhanced in this clearance pathway. The enzyme-mediated clearance pathway was tested with the use of recombinant IDE. However, there was no significant enhancement of digestion after 1 hour of incubation in the absence or presence of apoA-IV at $37^{\circ} \mathrm{C}$ in vitro (Figure $5 \mathrm{G}$ ). Moreover, mRNA levels of IDE and NEP, which are the two key factors in $A \beta$ digestion, did not show significant changes in both the presence and absence of apoA-IV in mice (Figure $5 \mathrm{H}$ ). These results indicate that apoA-IV does not increase $A \beta$ degradation mediated by IDE. Taken together, the above results show that apoA-IV can bind to $A \beta$, thus increasing the uptake of $A \beta$ by astrocytes. These results suggest that the appearance 
A

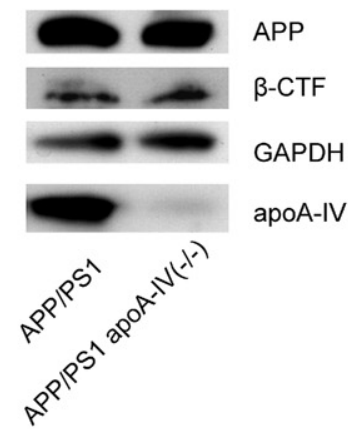

D

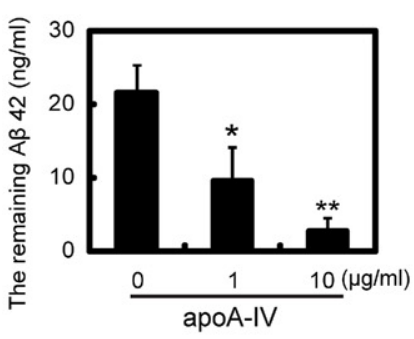

G

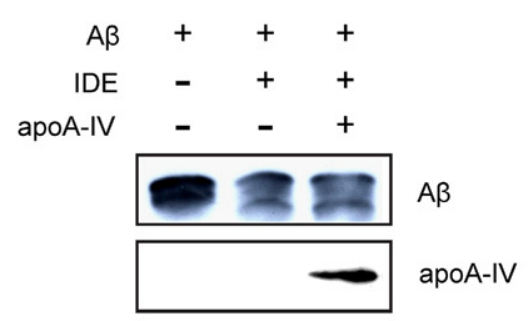

B

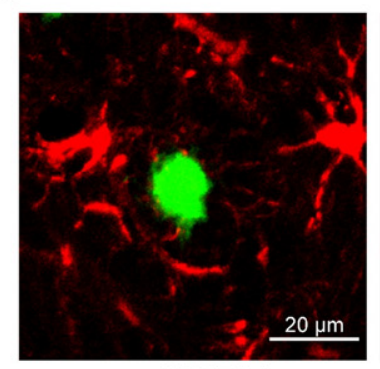

APP/PS1

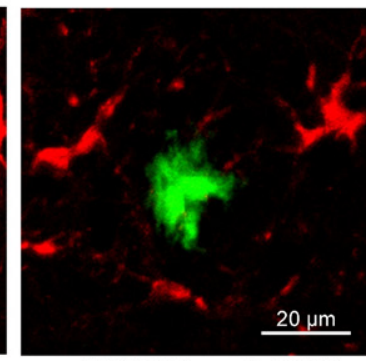

APP/PS1 apoA-IV(-/-)
C

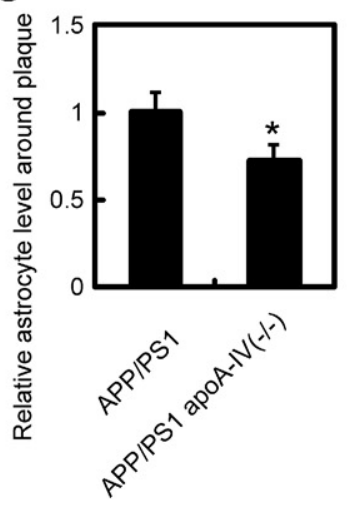

F

E

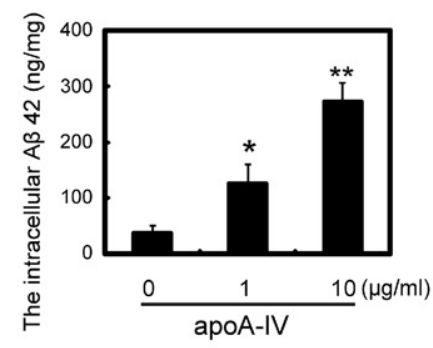

$\mathrm{H}$

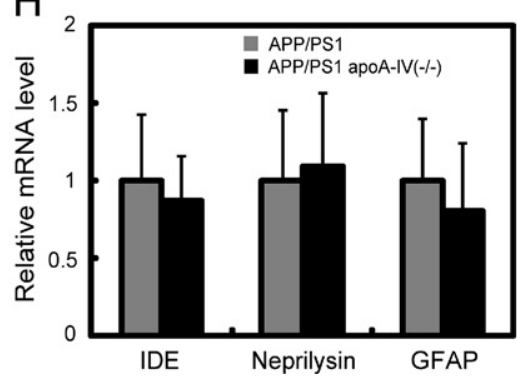

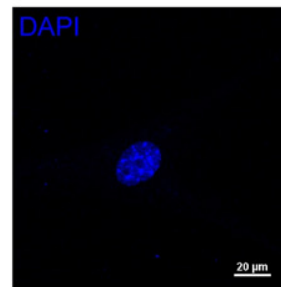
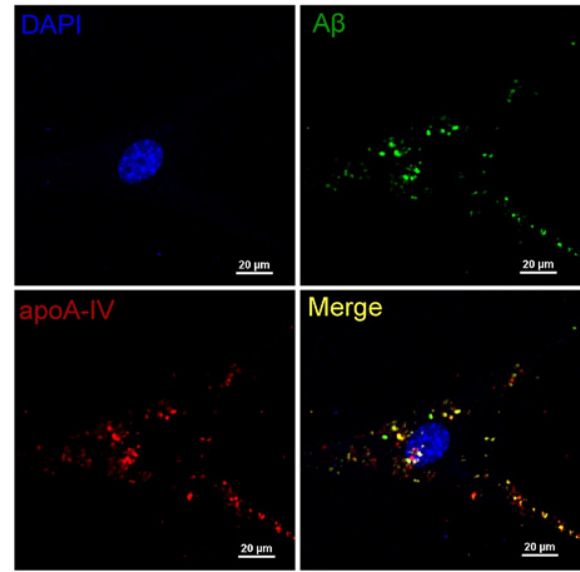

Figure 5. ApoA-IV is involved in A $\beta$ clearance mediated by astrocytes rather than the amyloidogenic pathway of APP processing. A: For detection of full-length APP, $\beta$-CTF, and apoA-IV, 8-month-old mice brain homogenates were tested by Western blotting, glyceraldehyde-3-phosphate dehydrogenase (GAPDH) was used as an internal control. B: A $\beta$ plaques surrounded by activated astrocytes were detected by immunofluorescence microscopy. The activated astrocytes were immunostained by anti-GFAP antibody and $(\mathbf{C})$ the relative astrocytes levels around the plaque (astrocytes level of APP/PS1 apoA-IV ${ }^{-}-/$astrocytes level of APP/PS1) were quantified, ${ }^{*} P<0.05$. D: The remaining amount of $A \beta 42$ in the culture medium was detected by ELISA after 24 hours of being co-incubated with primary adult mice astrocytes in the presence or absence of recombinant apoA-IV; ${ }^{*} P<0.05$; ${ }^{* *} P<0.01$. E: The intracellular level of A $\beta 42$ in cell lysates was detected by ELISA after 24 hours of being co-incubated with primary adult mice astrocytes in the presence or absence of recombinant apoA-IV. The data were normalized to total protein; ${ }^{*} P<0.05 ;{ }^{* *} P<0.01$. F: Immunostaining for apoA-IV and A $\beta$ in primary astrocytes after 24 hours of being co-incubated with exogenous apoA-IV and A $\beta 42$. G: A $\beta 42$ was incubated with $500 \mathrm{ng} / \mathrm{ml}$ recombinant IDE with or without recombinant apoA-IV for 1 hour. The reaction mixtures were then resolved by SDS-polyacrylamide gel electrophoresis and Western blotting for IDE, apoA-IV, and A $\beta$. H: The mRNA levels of IDE, NEP, and GFAP in the brains of 8 -month-old mice were measured by real-time PCR ( $n=8$ per group), and there are no significant differences between APP/PS1 and APP/PS1 apoA-IV ${ }^{-1-}$ mice.

of an accelerated AD pathogenesis in APP/PS1 apoA$\mathrm{IV}^{-1-}$ mice is caused by inefficient $A \beta$ uptake in the $A \beta$ clearance pathway mediated by astrocytes.

\section{Discussion}

The past two decades have witnessed an explosion in research of the role of apolipoproteins in $A D$ pathology. ${ }^{16,27,49-51}$ Importantly, CSF lipoproteins carry $A \beta,{ }^{15,51}$ which is the main component of senile amyloid plaques. Therefore, apoA-IV, as a typical CSF apolipoprotein, was tested with the use of the $A \beta$ hypothesisrelated $A D$ model. In our study, both in vitro and in vivo models were used to detect the pathologic role of apoA-IV in AD.

For the in vivo model of our study, APP/PS1 mice were selected on the basis of their rapid appearance of $A D$ phenotypes compared with the typical transgenic mouse models. ${ }^{42}$ The heterozygous mice APP/PS1 apoA-IV ${ }^{+/-}$ were also tested, and no significant gene dose-dependent effects were observed, although there was a trend among these three groups (see Supplemental Figure S6 at $h t t p: / /$ ajp.amjpathol.org). In this AD mouse model, both sexes show significantly increased plaque levels in APP/PS1 apoA-IV ${ }^{-1-}$ mice compared with APP/PS1 mice (see Supplemental Figure S7 at $h$ ttp://ajp.amjpathol.org). As shown in 
Figure 2, A and B, lack of apoA-IV causes the augmentation of neuron loss in both cortex and hippocampus, which can partially explain the learning deficiency in brain. The process of $A \beta$ aggregation and deposition may directly block the normal functions of neurons, ultimately causing neuronal death in and around the areas of plaques (see Supplemental Figure S8 at http://ajp.amjpathol.org). Meanwhile, we cannot preclude that projections from other regions filled with plaques indirectly cause neuronal death. AD model mice are often accompanied by a reduction of survival rates. When performing postmortem examinations, we observed cerebral hemorrhage in the 5X FAD mice. One of the possible explanations for early death may be cerebral vascular damage related to heavy $A \beta$ burden (see Supplemental Figure S9 at $h$ ttp://ajp.amipathol.org), which is caused by $A \beta$ deposition on the wall of blood vessels as reported in other transgenic mouse models. ${ }^{52,53}$

The co-localization study provides us with a clue that apoA-IV plays a role in $A \beta$ metabolism in vivo. To find out the roles of apoA-IV in the change of $A \beta$ accumulation, which is derived from the $A \beta$ metabolism regulation, we have detected the two processes of $A \beta$ metabolism: generation and clearance. As shown in Figure $5 \mathrm{~A}$, the results suggest that apoA-IV is not involved in the amyloidogenic pathway of $A \beta$ generation. Two very important pathways are involved in $A \beta$ clearance. One is the enzymatic degradation pathway, in which IDE and NEP play key roles in $A \beta$ digestion. However, the remaining amount of $A \beta$ is not significantly altered with or without apoA-IV in vitro (Figure $5 G$ ), indicating that enzymatic activity is not influenced by apoA-IV. In addition, the relative levels of IDE and NEP in vivo, reflected by detecting their mRNA levels, are not changed when apoA-IV is genetically ablated (Figure $5 \mathrm{H})$. Because apoA-IV does not influence the enzymatic activity, and the levels of both IDE and NEP are not changed by ablation of apoA-IV, we conclude that apoA-IV does not exert its function via this pathway. These data provide us with a hint that, although apoA-IV can bind to $A \beta$, it is not involved in enzymatic degradation of $A \beta$ in vivo.

The other important pathway is the glial cell-mediated clearance of $A \beta$. The study from Husemann and colleagues ${ }^{12}$ showed that astrocytes can uptake $A \beta$ in culture media. Interestingly, we found here that apoA-IV facilitates $A \beta$ uptake in the $A \beta$ clearance pathway mediated by astrocytes. The in vitro $A \beta$ uptake assay shows that exogenous apoA-IV added in culture media increases $A \beta$ uptake by astrocytes isolated from WT mice (Figure $5, D$ and $E$ ). However, $A \beta$ uptake by astrocytes isolated from apoA-IV ${ }^{-I-}$ mice shows a slight decrease compared with that from WT mice (see Supplemental Figure S5 at http://ajp.amjpathol.org), and the difference is not significant. Because apoA-IV was reported to exist in cerebrospinal fluid, ${ }^{54}$ this observation combined with our results imply that apoA-IV from cerebrospinal fluid, rather than that from astrocytes, plays a main role in $A \beta$ uptake in vivo. The result suggests that the regulation mechanism of apoA-IV is different from apoE, which can be highly secreted by astrocytes. The astrocytes isolated from apoE ${ }^{-1-}$ mice fail to uptake $A \beta$ in vitro. ${ }^{55}$ Although we cannot exclude the possibility of other mechanisms in

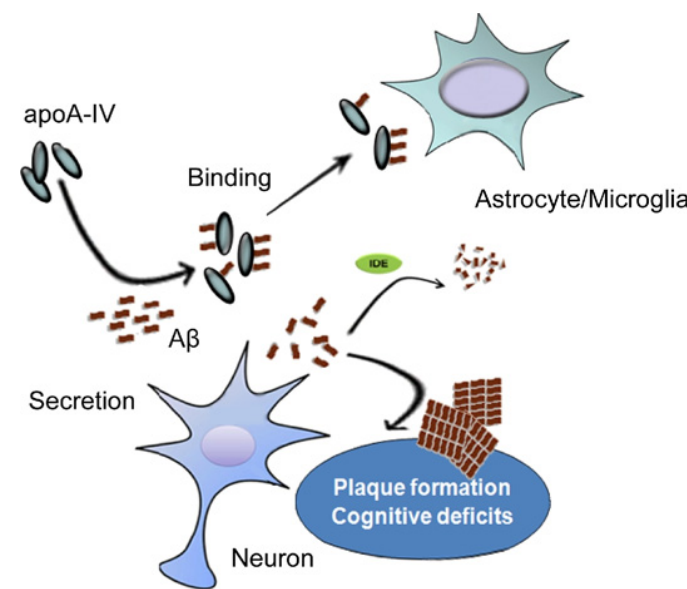

Figure 6. Molecular and cellular processes of apoA-IV in preventing AD pathogenesis. $\mathrm{A} \beta$ peptides produced by neurons and other cells in the brain may go into a variety of assemblies, some of which aggregate, deposit, and form plaques that impair synapses and neuronal cells and finally cause cognitive deficits. Build-up of pathogenic $\mathrm{A} \beta$ assemblies could result from increased production or from deficient clearance mechanisms. ApoA-IV in $\mathrm{CSF}$ can bind to $\mathrm{A} \beta$ and promote $\mathrm{A} \beta$ uptake in the glial cell-mediated clearance pathway, whereas it cannot increase $\mathrm{A} \beta$ production or digestion in the protease (IDE)-mediated clearance pathway.

$\mathrm{A} \beta$ metabolism to explain the uptake results, the binding data and the result of co-immunostaining in primary astrocytes provide us with evidence for a direct interaction between apoA-IV and A $\beta$. ApoA-IV is considered as a special apolipoprotein because it has been reported to exist in both the free form (not forming lipoprotein) and the lipoprotein form. ${ }^{56}$ Paul and colleagues ${ }^{55}$ reported that apoE can promote astrocyte co-locolization with deposited $A \beta$. Similarly, in the brain section from APP/PS1 apoA-IV ${ }^{-I-}$ mice, there are fewer activated astrocytes recruited to the areas of plaques, which suggests the possible role of apoA-IV in promoting astrocyte recruitment. Taking the above information into consideration, we conclude that apoA-IV acts as an $A \beta$-binding factor, mediating the clearance by astrocytes in the brain. In addition, the report from the Landreth group ${ }^{50}$ also shows that $\mathrm{HDL}$ can facilitate $\mathrm{A} \beta$ clearance. ApoA-IV may also form HDL and directly exert its function on astrocytes. This, together with our study, shows that one of the roles of apoA-IV in AD pathogenesis is to facilitate astrocytemediated $A \beta$ clearance. We cannot exclude the possible role of apoA-IV in the microglia-mediated pathway because microglia is also reported to be involved in $A \beta$ clearance pathway. ${ }^{50}$ Whether apoA-IV participates in the process mediated by microglia needs to be further investigated.

Our study shows that ablation of apoA-IV promotes amyloid formation and apoA-IV can facilitate $A \beta$ clearance, which provides a distinct mechanism from apoE, although some properties are similar. The $A \beta$ clearance in vivo is a complex process, which results from effects of various factors, including several apolipoproteins, and these factors may together maintain $A \beta$ metabolism in the brain. The present results provide us with clues to further investigate the pathogenesis of Alzheimer's disease. Recently, Paul and colleagues ${ }^{57}$ reported that the expression of knocked-in human apoE in vivo promotes amyloid 
formation in an isoform-specific way. Knocking-in human apoA-IV in the AD model mice will help us to better understand in vivo mechanism of apoA-IV in Alzheimer's disease.

In summary, our present study has identified that genetic ablation of apoA-IV accelerates Alzheimer's disease pathogenesis in an APP/PS1 transgenic mouse model (Figure 6). The results have shown a biological function of apoA-IV in the regulation of brain $A \beta$ metabolism to facilitate its clearance, offering new alternatives for the design of therapeutic strategies to treat $A D$.

\section{Acknowledgments}

We thank Yi Zhong, Ph.D., and Guosong Liu, M.D., Ph.D., for their helpful comments and insightful discussions. We appreciate Rosabel Bong for careful proofreading. We also appreciate members of the Luo laboratory for constructive suggestions and discussions throughout this work and Bipo Sun for routine laboratory management.

\section{References}

1. Hardy J, Selkoe DJ: The amyloid hypothesis of Alzheimer's disease: progress and problems on the road to therapeutics. Science 2002, 297:353-356

2. Selkoe D, Kopan R: Notch and presenilin: regulated intramembrane proteolysis links development and degeneration. Annu Rev Neurosci 2003, 26:565-597

3. Zheng $\mathrm{H}$, Koo EH: The amyloid precursor protein: beyond amyloid. Mol Neurodeg 2006, 1:5

4. Vassar R, Bennett BD, Babu-Khan S, Kahn S, Mendiaz EA, Denis $P$, Teplow DB, Ross S, Amarante P, Loeloff R, Luo Y, Fisher S, Fuller J, Edenson S, Lile J, Jarosinski MA, Biere AL, Curran E, Burgess T, Louis JC, Collins F, Treanor J, Rogers G, Citron M: Beta-secretase cleavage of Alzheimer's amyloid precursor protein by the transmembrane aspartic protease BACE. Science 1999, 286:735-741

5. De Strooper B, Saftig P, Craessaerts K, Vanderstichele H, Guhde G, Annaert W, Von Figura K, Van Leuven F: Deficiency of presenilin-1 inhibits the normal cleavage of amyloid precursor protein. Nature 1998, 391:387-390

6. Wolfe MS, Xia W, Ostaszewski BL, Diehl TS, Kimberly WT, Selkoe DJ: Two transmembrane aspartates in presenilin-1 required for presenilin endoproteolysis and gamma-secretase activity. Nature 1999, 398: 513-517

7. Hatten ME, Liem RK, Shelanski ML, Mason CA: Astroglia in CNS injury. Glia 1991, 4:233-243

8. Montgomery DL: Astrocytes: form, functions, and roles in disease. Vet Pathol 1994, 31:145-167

9. Shao Y, McCarthy KD: Plasticity of astrocytes. Glia 1994, 11:147-155

10. al-Ali SY, al-Hussain SM: An ultrastructural study of the phagocytic activity of astrocytes in adult rat brain. J Anat 1996, 188 (Pt 2):257262

11. Guillaume D, Bertrand P, Dea D, Davignon J, Poirier J: Apolipoprotein $E$ and low-density lipoprotein binding and internalization in primary cultures of rat astrocytes: isoform-specific alterations. J Neurochem 1996, 66:2410-2418

12. Wyss-Coray T, Loike JD, Brionne TC, Lu E, Anankov R, Yan F, Silverstein SC, Husemann J: Adult mouse astrocytes degrade amyloid-beta in vitro and in situ. Nat Med 2003, 9:453-457

13. Wegiel J, Wang KC, Tarnawski M, Lach B: Microglia cells are the driving force in fibrillar plaque formation, whereas astrocytes are a leading factor in plague degradation. Acta Neuropathol 2000, 100 : 356-364

14. Koudinov A, Matsubara E, Frangione B, Ghiso J: The soluble form of Alzheimer's amyloid beta protein is complexed to high density lipoprotein 3 and very high density lipoprotein in normal human plasma. Biochem Biophys Res Commun 1994, 205:1164-1171
15. Koudinov AR, Koudinova NV, Kumar A, Beavis RC, Ghiso J: Biochemical characterization of Alzheimer's soluble amyloid beta protein in human cerebrospinal fluid: association with high density lipoproteins. Biochem Biophys Res Commun 1996, 223:592-597

16. Koudinov AR, Berezov TT, Kumar A, Koudinova NV: Alzheimer's amyloid beta interaction with normal human plasma high density lipoprotein: association with apolipoprotein and lipids. Clin Chim Acta 1998, 270:75-84

17. Strittmatter WJ, Saunders AM, Schmechel D, Pericak-Vance M, Enghild J, Salvesen GS, Roses AD: Apolipoprotein E: high-avidity binding to beta-amyloid and increased frequency of type 4 allele in late-onset familial Alzheimer disease. Proc Natl Acad Sci U S A 1993, 90:19771981

18. Corder EH, Saunders AM, Strittmatter WJ, Schmechel DE, Gaskell PC, Small GW, Roses AD, Haines JL, Pericak-Vance MA: Gene dose of apolipoprotein E type 4 allele and the risk of Alzheimer's disease in late onset families. Science 1993, 261:921-923

19. Fagan AM, Holtzman DM, Munson G, Mathur T, Schneider D, Chang LK, Getz GS, Reardon CA, Lukens J, Shah JA, LaDu MJ: Unique lipoproteins secreted by primary astrocytes from wild type, apoE (-/-) and human apoE transgenic mice. J Biol Chem 1999, 274:3000130007

20. Kim J, Basak JM, Holtzman DM: The role of apolipoprotein E in Alzheimer's disease. Neuron 2009, 63:287-303

21. Ma J, Yee A, Brewer HB Jr, Das S, Potter H: Amyloid-associated proteins alpha 1-antichymotrypsin and apolipoprotein E promote assembly of Alzheimer beta-protein into filaments. Nature 1994, 372 92-94

22. Wisniewski T, Castano EM, Golabek A, Vogel T, Frangione B: Acceleration of Alzheimer's fibril formation by apolipoprotein $E$ in vitro. Am J Pathol 1994, 145:1030-1035

23. Bales KR, Verina T, Dodel RC, Du Y, Altstiel L, Bender M, Hyslop P, Johnstone EM, Little SP, Cummins DJ, Piccardo P, Ghetti B, Paul SM: Lack of apolipoprotein $E$ dramatically reduces amyloid beta-peptide deposition. Nat Genet 1997, 17:263-264

24. Bales KR, Verina T, Cummins DJ, Du Y, Dodel RC, Saura J, Fishman CE, DeLong CA, Piccardo P, Petegnief V, Ghetti B, Paul SM: Apolipoprotein $E$ is essential for amyloid deposition in the APP(V717F) transgenic mouse model of Alzheimer's disease. Proc Natl Acad Sci U S A 1999, 96:15233-15238

25. Beffert $U$, Poirier J: ApoE associated with lipid has a reduced capacity to inhibit beta-amyloid fibril formation. Neuroreport 1998, 9:33213323

26. Wood SJ, Chan W, Wetzel R: Seeding of A beta fibril formation is inhibited by all three isotypes of apolipoprotein E. Biochemistry 1996 $35: 12623-12628$

27. DeMattos RB, O'Dell MA, Parsadanian M, Taylor JW, Harmony JA, Bales KR, Paul SM, Aronow BJ, Holtzman DM: Clusterin promotes amyloid plaque formation and is critical for neuritic toxicity in a mouse model of Alzheimer's disease. Proc Natl Acad Sci U S A 2002, 99:10843-10848

28. Fagan AM, Christopher E, Taylor JW, Parsadanian M, Spinner M, Watson M, Fryer JD, Wahrle S, Bales KR, Paul SM, Holtzman DM: ApoAl deficiency results in marked reductions in plasma cholesterol but no alterations in amyloid-beta pathology in a mouse model of Alzheimer's disease-like cerebral amyloidosis. Am J Pathol 2004 165:1413-1422

29. Beisiegel U, Utermann G: An apolipoprotein homolog of rat apolipoprotein A-IV in human plasma. Isolation and partial characterization. Eur J Biochem 1979, 93:601-608

30. Weinberg RB, Scanu AM: Isolation and characterization of human apolipoprotein A-IV from lipoprotein-depleted serum. J Lipid Res 1983, 24:52-59

31. Goldberg IJ, Scheraldi CA, Yacoub LK, Saxena U, Bisgaier CL: Lipoprotein ApoC-II activation of lipoprotein lipase. Modulation by apolipoprotein A-IV. J Biol Chem 1990, 265:4266-4272

32. Sato K, Takahashi Y, Takahashi T, Katoh N, Akiba Y: Identification of factors regulating lipoprotein lipase catalyzed hydrolysis in rats with the aid of monoacid-rich lipoprotein preparations(1). J Nutr Biochem 2002, 13:528

33. Vowinkel T, Mori M, Krieglstein CF, Russell J, Saijo F, Bharwani S, Turnage RH, Davidson WS, Tso P, Granger DN, Kalogeris TJ: Apolipoprotein A-IV inhibits experimental colitis. J Clin Invest 2004, 114 260-269 
34. Qin X, Swertfeger DK, Zheng S, Hui DY, Tso P: Apolipoprotein AIV: a potent endogenous inhibitor of lipid oxidation. Am J Physiol 1998, 274:H1836-H1840

35. Bergstrom J, Murphy C, Eulitz M, Weiss DT, Westermark GT, Solomon A, Westermark P: Codeposition of apolipoprotein A-IV and transthyretin in senile systemic (ATTR) amyloidosis. Biochem Biophys Res Commun 2001, 285:903-908

36. Bergstrom J, Murphy CL, Weiss DT, Solomon A, Sletten K, Hellman U, Westermark P: Two different types of amyloid depositsapolipoprotein A-IV and transthyretin-in a patient with systemic amyloidosis. Lab Invest 2004, 84:981-988

37. Duverger N, Tremp G, Caillaud JM, Emmanuel F, Castro G, Fruchart JC, Steinmetz A, Denefle P: Protection against atherogenesis in mice mediated by human apolipoprotein A-IV. Science 1996, 273:966-968

38. Fujimoto K, Cardelli JA, Tso P: Increased apolipoprotein A-IV in rat mesenteric lymph after lipid meal acts as a physiological signal for satiation. Am J Physiol 1992, 262:G1002-G1006

39. Fujimoto K, Fukagawa K, Sakata T, Tso P: Suppression of food intake by apolipoprotein A-IV is mediated through the central nervous system in rats. J Clin Invest 1993, 91:1830-1833

40. Csaszar A, Kalman J, Szalai C, Janka Z, Romics L: Association of the apolipoprotein A-IV codon 360 mutation in patients with Alzheimer's disease. Neurosci Lett 1997, 230:151-154

41. Merched A, Xia Y, Papadopoulou A, Siest G, Visvikis S: Apolipoprotein AIV codon 360 mutation increases with human aging and is not associated with Alzheimer's disease. Neurosci Lett 1998, 242:117119

42. Oakley H, Cole SL, Logan S, Maus E, Shao P, Craft J, GuillozetBongaarts A, Ohno M, Disterhoft J, Van Eldik L, Berry R, Vassar R: Intraneuronal beta-amyloid aggregates, neurodegeneration, and neuron loss in transgenic mice with five familial Alzheimer's disease mutations: potential factors in amyloid plaque formation. J Neurosci 2006, 26:10129-10140

43. Vorhees CV, Williams MT: Morris water maze: procedures for assessing spatial and related forms of learning and memory. Nat Protoc 2006, 1:848-858

44. Schmidt SD, Jiang Y, Nixon RA, Mathews PM: Tissue processing prior to protein analysis and amyloid-beta quantitation. Methods Mol Biol 2005, 299:267-278

45. Pearson K, Saito H, Woods SC, Lund-Katz S, Tso P, Phillips MC, Davidson WS: Structure of human apolipoprotein A-IV: a distinct domain architecture among exchangeable apolipoproteins with potential functional implications. Biochemistry 2004, 43:10719-10729

46. Murphy BF, Kirszbaum L, Walker ID, d'Apice AJ: SP-40,40, a newly identified normal human serum protein found in the SC5b-9 complex of complement and in the immune deposits in glomerulonephritis. J Clin Invest 1988, 81:1858-1864

47. Leissring MA, Farris W, Chang AY, Walsh DM, Wu X, Sun X, Frosch MP, Selkoe DJ: Enhanced proteolysis of beta-amyloid in APP transgenic mice prevents plaque formation, secondary pathology, and premature death. Neuron 2003, 40:1087-1093

48. Ganguli M, Dodge HH, Shen CY, Pandav RS, DeKosky ST: Alzheimer disease and mortality: a 15-year epidemiological study. Arch Neurol 2005, 62:779-784

49. Matsubara E, Frangione B, Ghiso J: Characterization of apolipoprotein J-Alzheimer's A beta interaction. J Biol Chem 1995, 270:75637567

50. Jiang Q, Lee CY, Mandrekar S, Wilkinson B, Cramer P, Zelcer N, Mann K, Lamb B, Willson TM, Collins JL, Richardson JC, Smith JD, Comery TA, Riddell D, Holtzman DM, Tontonoz P, Landreth GE: ApoE promotes the proteolytic degradation of Abeta. Neuron 2008, 58:681693

51. Biere AL, Ostaszewski B, Stimson ER, Hyman BT, Maggio JE, Selkoe DJ: Amyloid beta-peptide is transported on lipoproteins and albumin in human plasma. J Biol Chem 1996, 271:32916-32922

52. Calhoun $M E$, Burgermeister $P$, Phinney $A L$, Stalder $M$, Tolnay $M$ Wiederhold KH, Abramowski D, Sturchler-Pierrat C, Sommer B Staufenbiel M, Jucker M: Neuronal overexpression of mutant amyloid precursor protein results in prominent deposition of cerebrovascular amyloid. Proc Natl Acad Sci U S A 1999, 96:14088-14093

53. Van Dorpe J, Smeijers L, Dewachter I, Nuyens D, Spittaels K, Van Den Haute C, Mercken M, Moechars D, Laenen I, Kuiperi C, Bruynseels K, Tesseur I, Loos R, Vanderstichele H, Checler F, Sciot R, Van Leuven F: Prominent cerebral amyloid angiopathy in transgenic mice overexpressing the london mutant of human APP in neurons. Am J Pathol 2000, 157:1283-1298

54. Liu M, Doi T, Shen L, Woods SC, Seeley RJ, Zheng S, Jackman A, Tso $P$ : Intestinal satiety protein apolipoprotein AIV is synthesized and regulated in rat hypothalamus. Am $\mathrm{J}$ Physiol Regul Integr Comp Physiol 2001, 280:R1382-R1387

55. Koistinaho M, Lin S, Wu X, Esterman M, Koger D, Hanson J, Higgs R, Liu F, Malkani S, Bales KR, Paul SM: Apolipoprotein E promotes astrocyte colocalization and degradation of deposited amyloid-beta peptides. Nat Med 2004, 10:719-726

56. Bisgaier CL, Sachdev OP, Megna L, Glickman RM: Distribution of apolipoprotein A-IV in human plasma. J Lipid Res 1985, 26:11-25

57. Bales KR, Liu F, Wu S, Lin S, Koger D, DeLong C, Hansen JC, Sullivan PM, Paul SM: Human APOE isoform-dependent effects on brain beta-amyloid levels in PDAPP transgenic mice. J Neurosci 2009, 29:6771-6779 